\title{
إيجاد هقاسات قياسية لجسم المرأة السعودية
}

\author{
اعــــلـاد \\ د. هند محمد عمر أربعين \\ د. عزة محمد حلدمـــــإبراهيم \\ أستاذ مساعد الملابس والنسيج \\ ملدرس الملابس والنسيج - كلية \\ كلية التربية للاقتصاد المنزبي بمكة المكرمة \\ الاقتصاد المنزبي _ جامعة حلوان
}

مجلة بحوث التربية النوعية - جامعة المنصورة

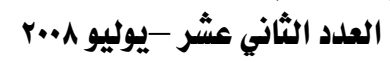




\section{إيباد هقاسات قياسية لبسم المرأة السعودية}

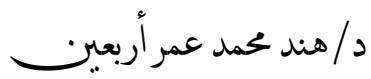

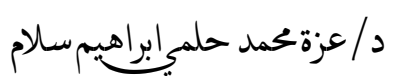

\section{קטגט}

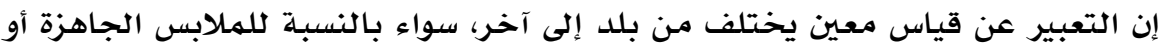

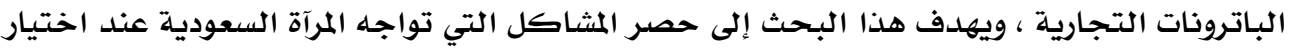

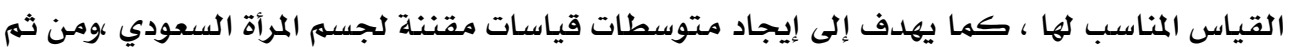

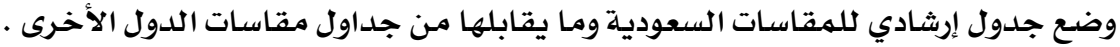
واتبع البحث المنهج الوصفي التحليلي ،حيث طبقت الاستبانة على عينة استطلاعية عددها

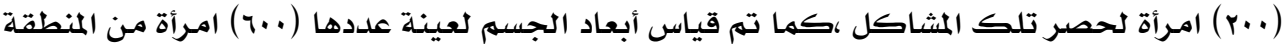
الغربية (مكة المكرمة - جدة - الطائف) لإيجاد متتوسطات قياسات للمرأة السعودية ومن ثم تم ريطها

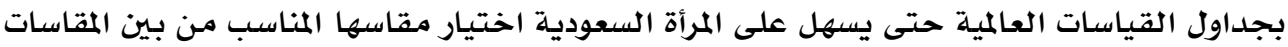

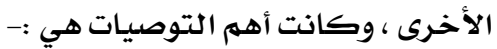
ا- تزويد هيئة المواصفات القياسية السعودية بجدول قياسات المرأة السعودية لتزويد المصانع

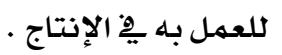

r- تصميه بطاقة إرشادية لمقاسات الملابس السعودية والمقاسات التي تقابلها من الدول الأخرى

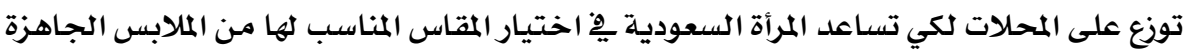

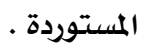

r- إنشاء مصانع وطنية تنتج ملابس بمقاسات المرأة السعودية 
تحرص العديد من الدول المتقدمة على إرساء معايير ومعدلات النمو وتطور الأجسام

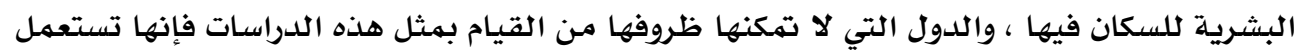

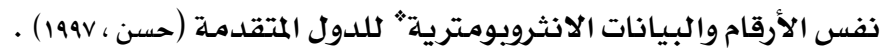

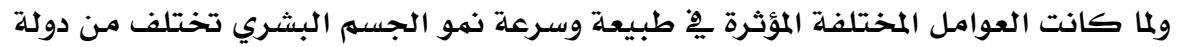

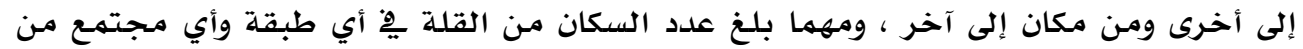

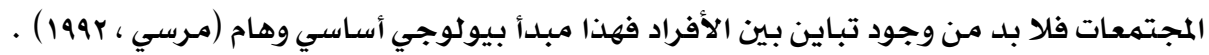
واستخدام مقاسات قياسية وهو مـا يعرف بجداول المقاسات القياسية Standard Measurement Chart

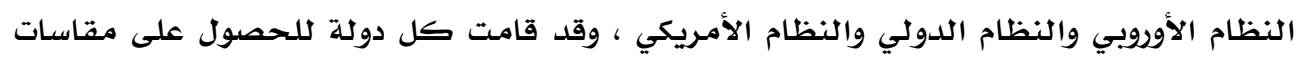

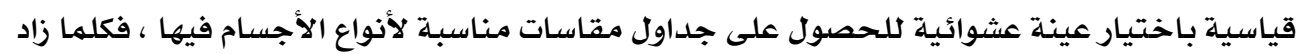
أفراد العينة كلما كانت جداول القياسات مناسبة ودقيقة وذات فاعلية (agioello , 1989) .

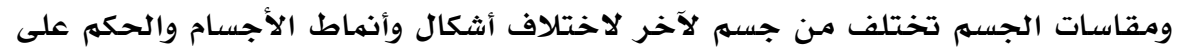

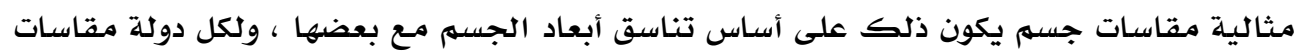

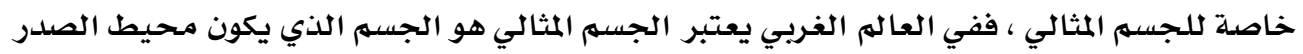

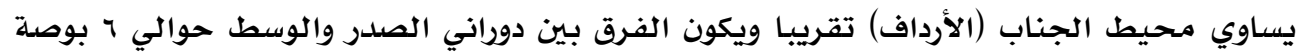
. (fernon, 1990)

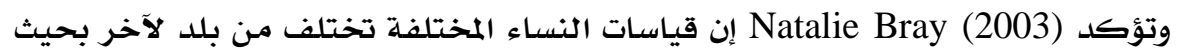

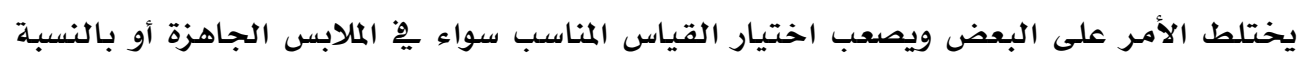

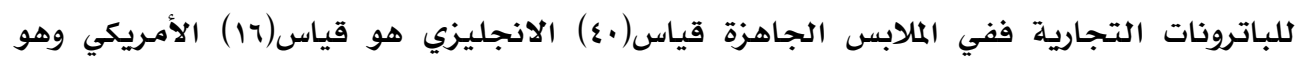

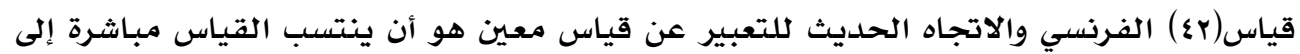

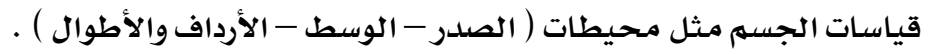

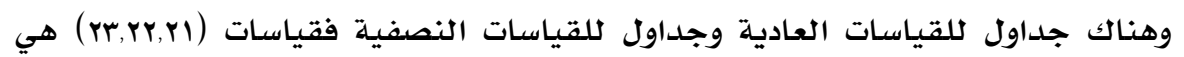

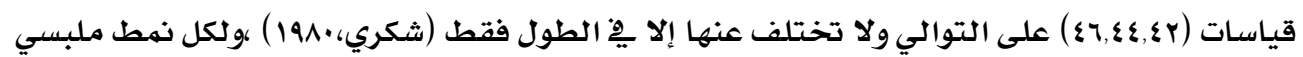

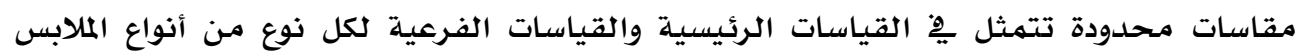

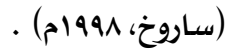

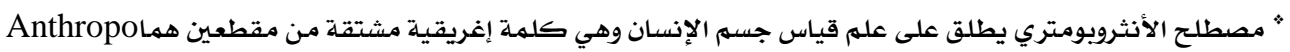
تعني إنسان وMetry تعني القياس 


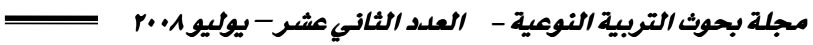

وعند مقارنة جداول القياسات المقننة تستخدم أريعة قياسات(محيط الصددر. محيط

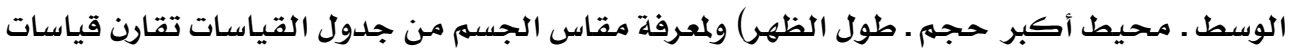

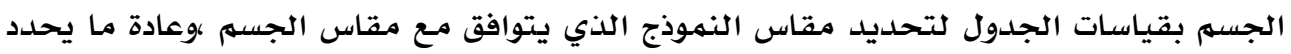
المقاس بواسطة قياس الصدر (رزق ، ب... (r) .

وقد اهتمت الهيئة العربية السعودية للمواصفات والمقاييس (التي أنشأت بموجب المرسوم

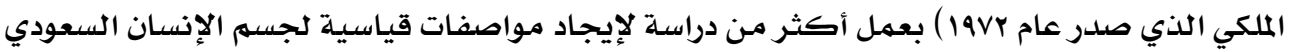

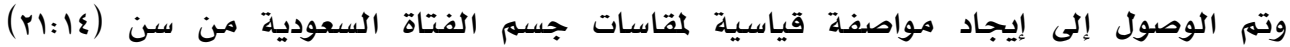

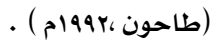

وبفحص جداول البلاد المختلفة نجد أن كل دولة تحاول أن تصنع جداول تتفق مـع أجسام

أفردها وهذا مـا دعي الباحثتان إلى محاولة إيجاد متوسطات لقياسات المرأة السعودية .

توضـع جداول القياسات على أساس الدراسـات الشاملة على الأجسام المختلفة ، ولكل دولة

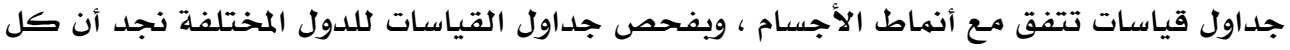

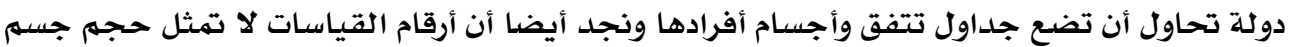

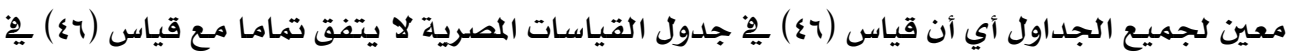

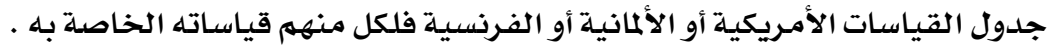
ومن خلال الدراسات الاستطلاعية وجد أن هناك مشكلات تواجه المرأة السعودية عند اختيار

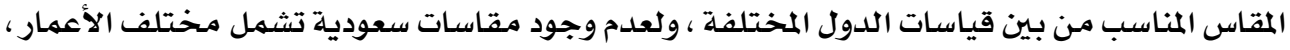

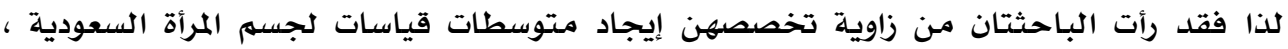
وتتلخص مشكلة البحث فِ التساؤلات التالية :

ا ـ ما المشاكل التي تواجه المرأة السعودية عند اختيار القياس المناسب ؟ ؟

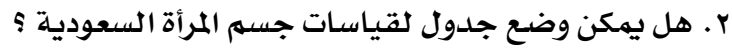
r. هل توجد علاقة بين قياسات جسم المرأة السعودية والقياسات الدولئ الدولية ؟

\section{أهداف البحث:}

ا ـ التعرف على الأسلوب المتبع يْ تحديد قياسات شراء الملابس الجاهزة .

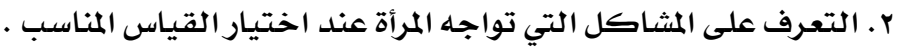

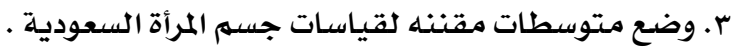

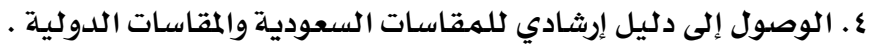




\section{تتحلد أهمية البحث ـِ النقاط التالية:}

ا. ـ تسهيل عملية اختيار المقاس المناسب لجسه المرأة السعودية من بين المقاسات الدولية .

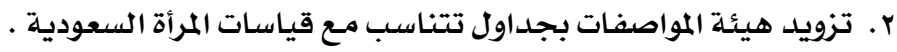

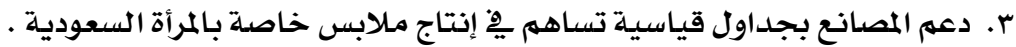

\section{حدود البـمث:}

يقتــر البحث الحـالي علـى إيجـاد متوسـطات لقياسـات المرأة السعوديـة ومعرفـة علاقتهـا

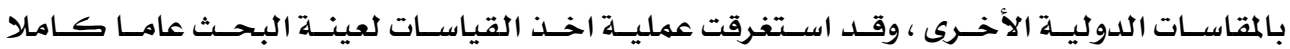
.

\section{مصالمات البمث:}

\section{• مقاسات: Size}

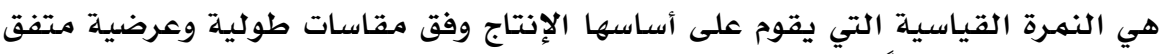

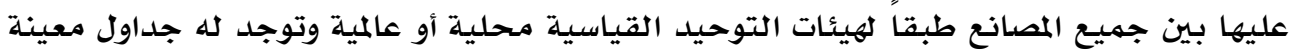

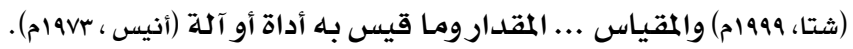

\section{measurement : القياس}

هو عبارة عن طريقة معرفة عدد وحدات القياس الموجودة ِِّ شئ ما وشريط القياس هو

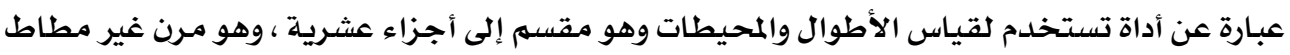

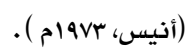

\section{measurable : القياسية}

ويقصد بها تحديد الخصائص التي ينبغي توفرها يِّ السلعة لتناسب الغرض الذي الذي أنتجت

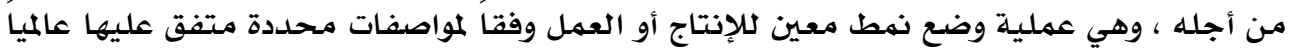
(المواصفات ، من اجله ، وهي)

\section{الدراسات السابقة المواسفة مشاتة}

نظرا لأهمية القياسات بالنسبة لصناعة الملابس الجاهزة فقد اهتم الكثير من الباحثين

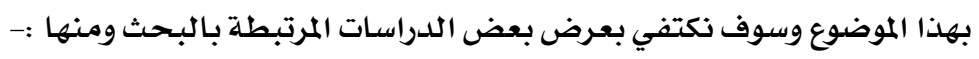

1- دراسة مصطفى ،انجاهان حسن (19v0م) عن "وضع أماميات القياسات لتصنيع الملابس

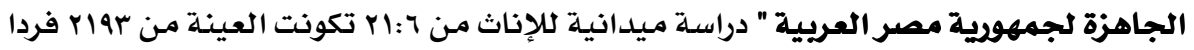

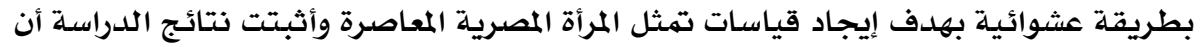

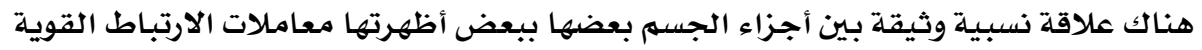

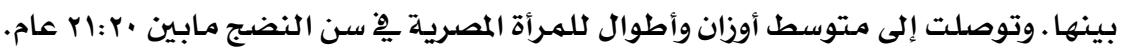




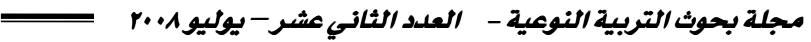

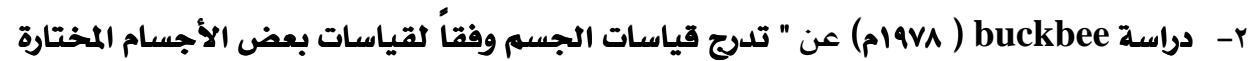

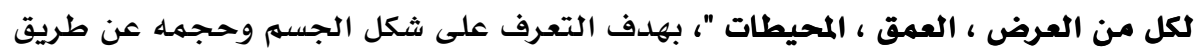

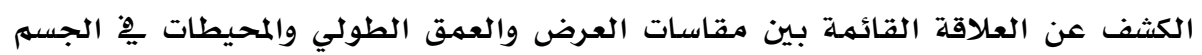

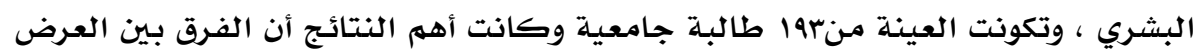

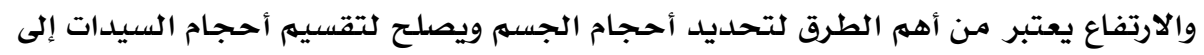

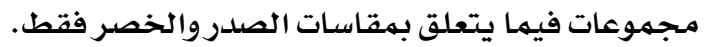

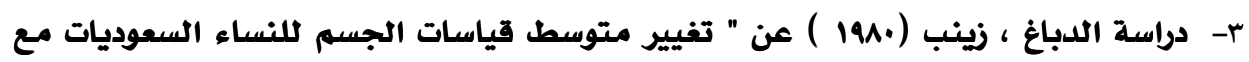

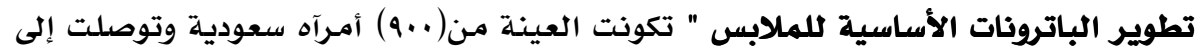

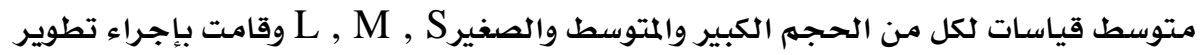

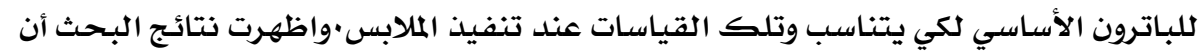

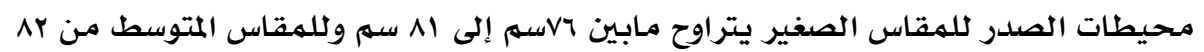

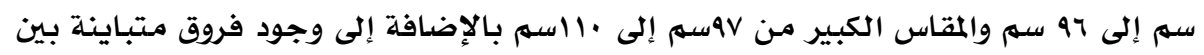

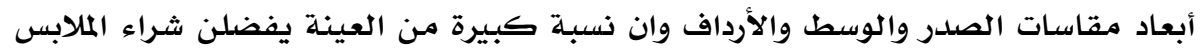

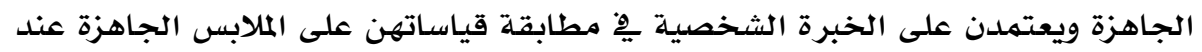
الشراء. ع- - دراسة Kap-Sum (1984) عن " مقارنة بين القياسات الجسمية للنساء الشرقيات و

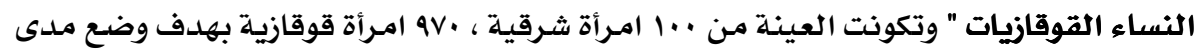

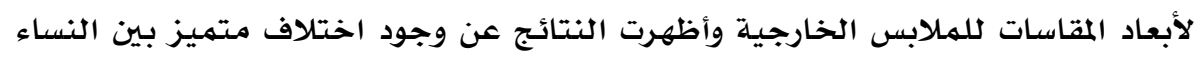

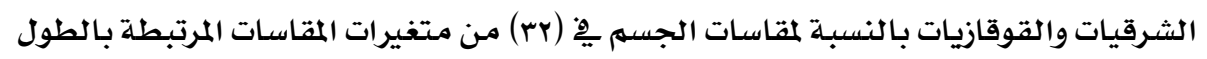

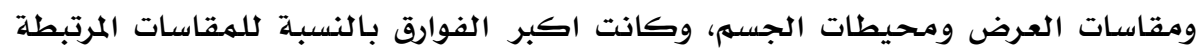
بالطول . ماسنات

ه- دراسة نصار،عايدة محمد (19AV) عن " وضع أساسيات مقننة لجسم المرأة المصرية لبناء

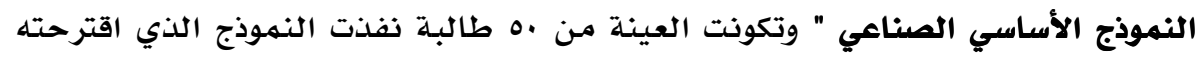

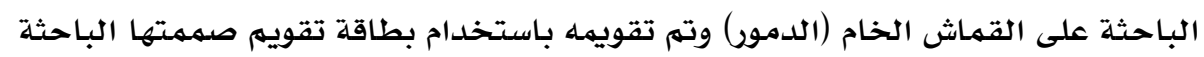

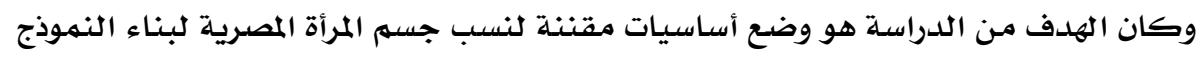

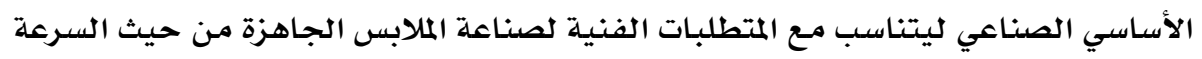

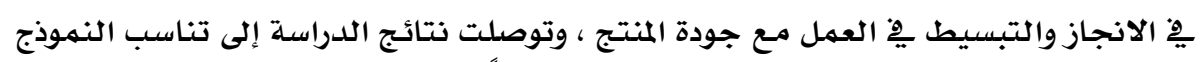

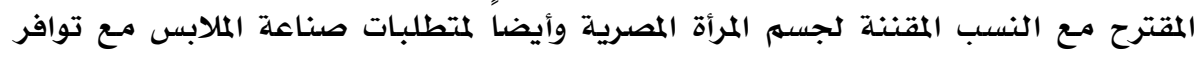

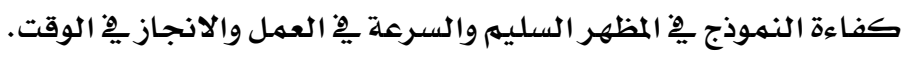
1- دراسة التركي،هدى سلطان (19MM) عن " المواصفات القياسية التجارية لمقاييس ملابس

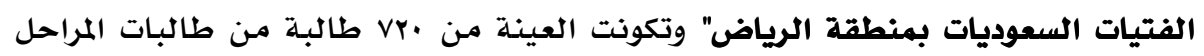

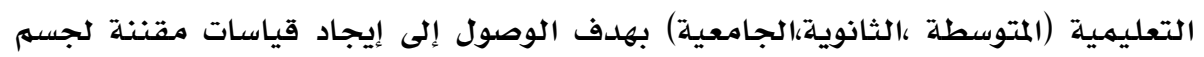


الفتاه السعودية وأسفرت النتائج عن الوصول إلى ستتة مواصفات قياسية ملائمة لمواصفات أجسام الفتيات السعوديات.

V- راسة طاحون،سامية عبد العظيم والتركي،هدى سلطان(199ץ/م) عن " المواصفات القياسية النسائية ودورها ـِ التبادل التجاري دراسة مقارنة بين المواصفات القياسية السعودية

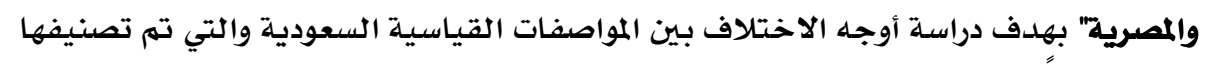

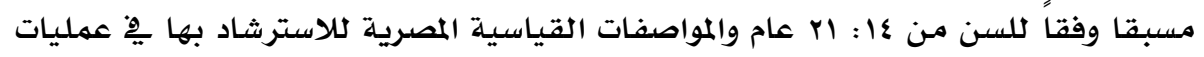

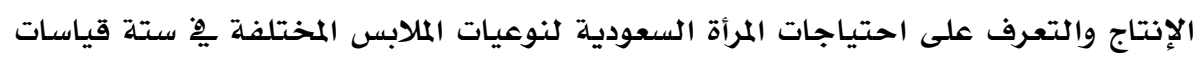

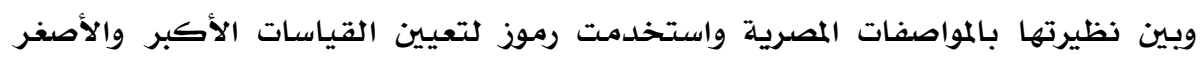

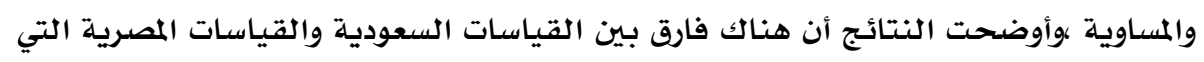

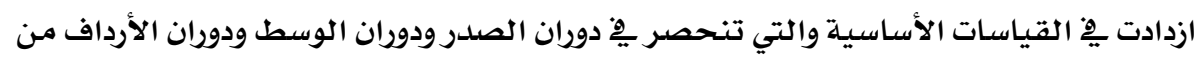

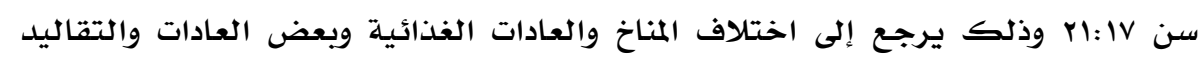

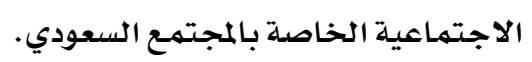

1- دراسة ساروخ ، صفية عبد العزيز قطب (1994م ) عن" الملابس الجاهزة ، مشكلاتها وعلاقتها

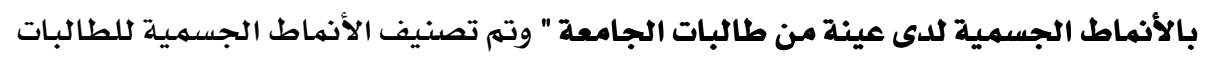

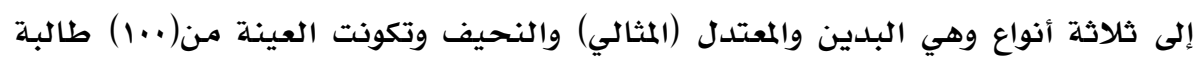

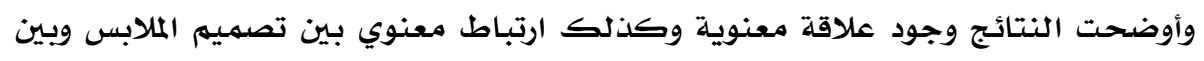

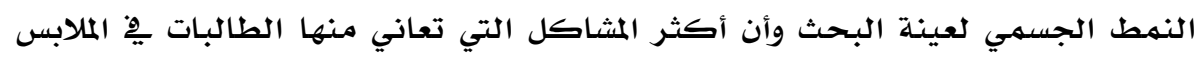
الجاهزة يِّ منطقة الصدر ومنطقة الأرداف.

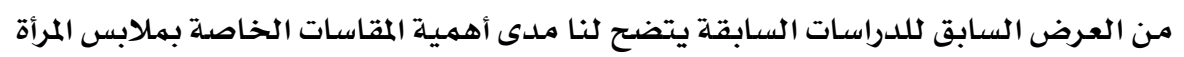

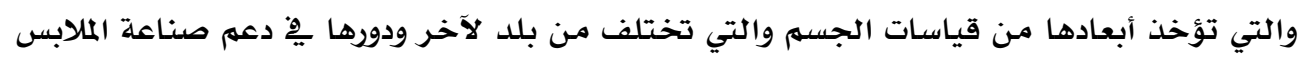

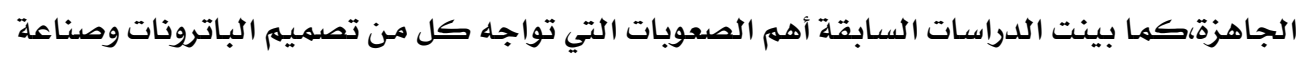

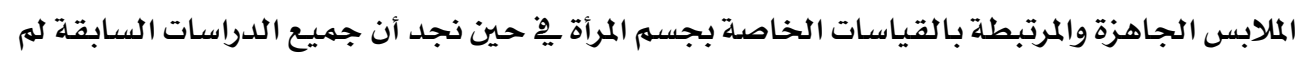

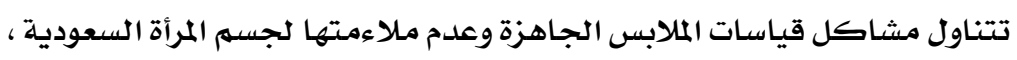
وهذا مـا تسعى الدراسة الحالية إلى تحقيقه من خلال إيجاد متوسطات لقياسـات جسهم المرأة

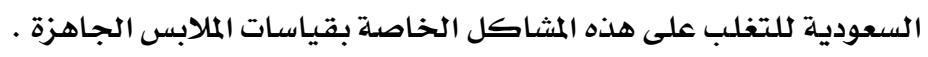
هزوض البحث: البحث: يتبع البحث المنهج الوصفي التحليلي والميداني

1. ـ هناك أسلوب خاص بالمرأة السعودية تختار على أساسـه مقاس الملابس

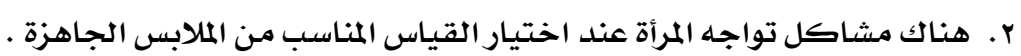

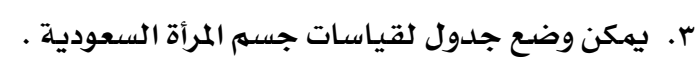

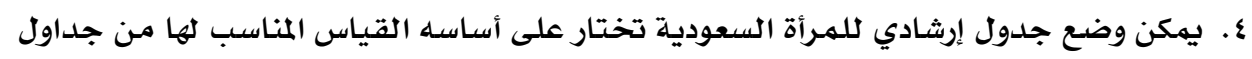
قياسات الدول الأخرى . 


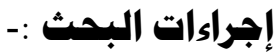 \\ أولا : تصميه أدوات البحث :- \\ تكونت أدوات البحث من :

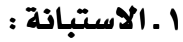

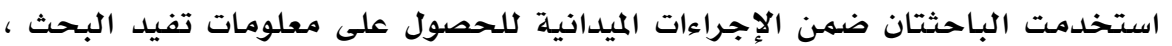

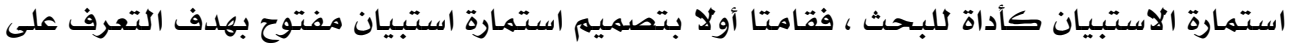

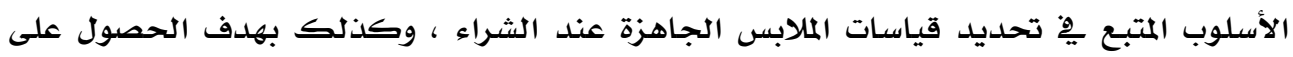

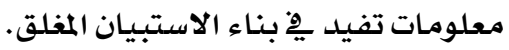

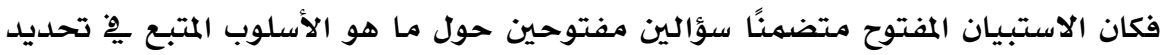

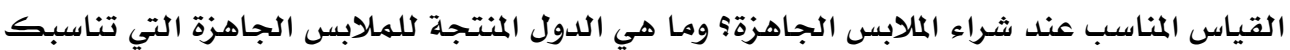

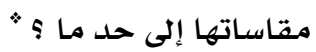

أما الاستبيان المغلق فبني على أساس ما تم جمعهل واحتوى على بيانات شخصية عن : (السن

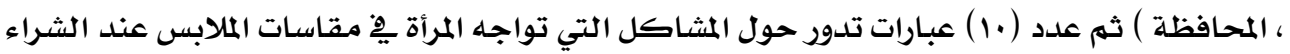

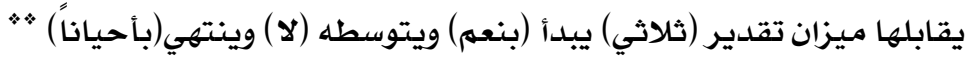
وللتحقق من صدق الاستبانة :

تم تحكيم الاستبانة بواسطة عدد من الأساتذة المتخصصين بقسم الملابس والنسيج للتأكد

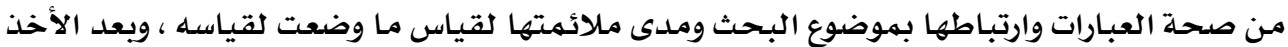

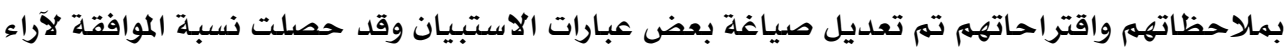

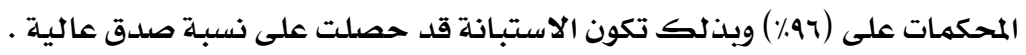

ثبات الاستتبانة :

اتبّعَتَ الباحثتان القياس الإحصائي لقياس الثبات، وذلك بطريقة التجزئة النصفية ،

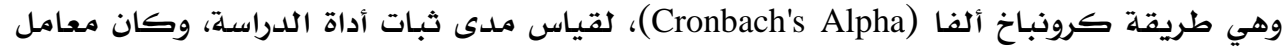

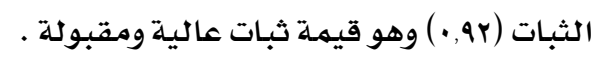

\section{r . استمارة تسجيل القياسات للمرأة السعوديةه+ه}

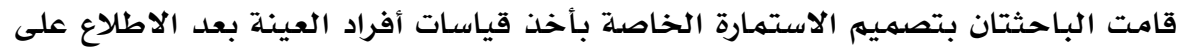

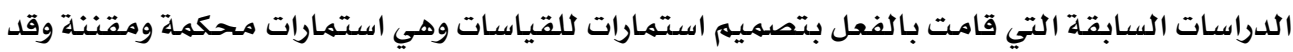

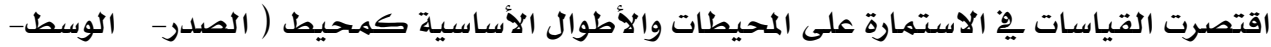

$$
\begin{aligned}
& \text { " الملحق(1) الاستبيان المفتوح (ب) الاستيان المغاق }
\end{aligned}
$$

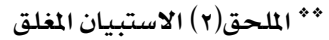

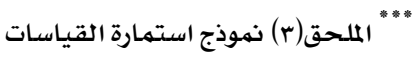


البطن - الجناب - الدراع ) وطول ( الصدر - الظهر - الكوع - الكم ) والتي أوصت بها نتالي براي

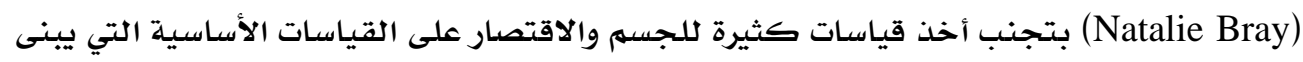

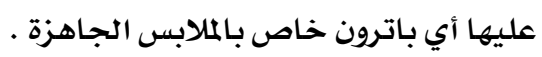

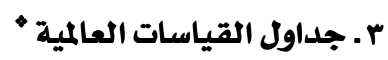

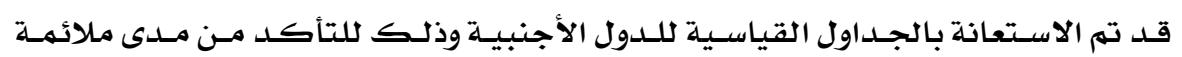

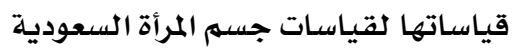

ثانيا : تحديلد العينة

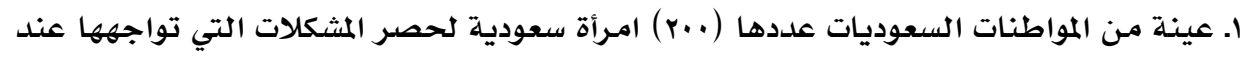

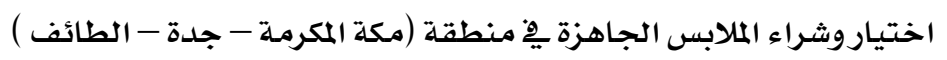

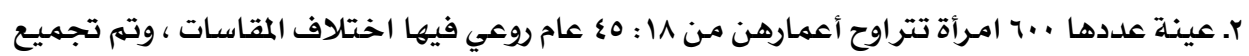

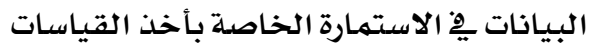

\begin{tabular}{|c|c|c|c|c|}
\hline النسبـة & العدد ( ... & النسبـة & العدد ( . .7) & المحافظة \\
\hline$\%$. & $1 \ldots$ & $\% \varepsilon 1,7$ & ro. & مكة المكرمـة \\
\hline$\%$ Yo & 0. & \% & $r \ldots$ & جدة \\
\hline$\%$ Yo & 0. & $\%$ Yo & 10. & الطائف \\
\hline
\end{tabular}

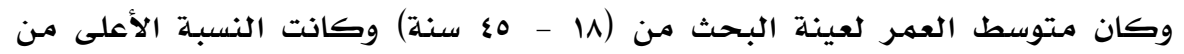

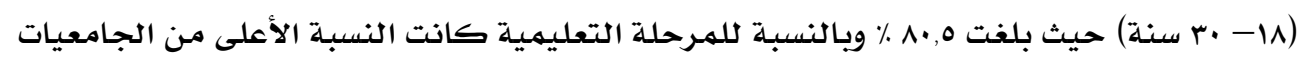

وبلغت 0

ثالثا : التطبيق وتوزيع الاستبانات

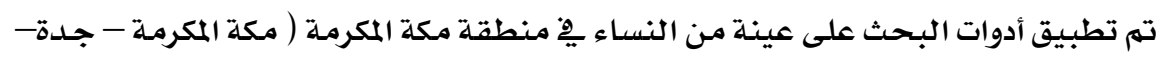

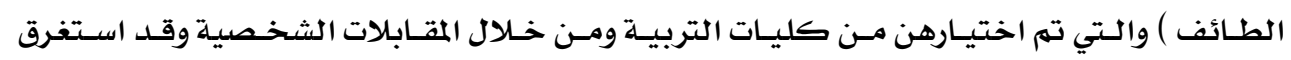

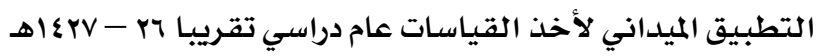

رابعا : المعالجة الإحصائية الميلية انسية القيلية

استخدم يِّ هذا البحث النسب المئوية والتكرارات يِّ معالجة البيانات

" الملحق(ع) نماذج الجداول 
نتائج البحث ومناقشتها :-

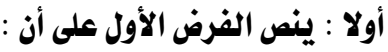

"هناك أسلوب خاص بالمرأة السعودية تختار على أساسه مقاس الملابس"

وللتحقق من صحة هذا الفرض باستخدام النسب المئوية والتكرارات كما يوضحها الجدول

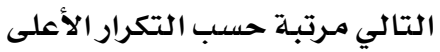

جدول رقم ( ) ( )

يوضتح الأسلوب المتبـع ِِ تحديد القياس المناسب والمطابق لجسه المرأة السعودية

\begin{tabular}{|c|c|c|c|}
\hline \multicolumn{2}{|c|}{ التكرارات والنسب } & \multirow{2}{*}{ 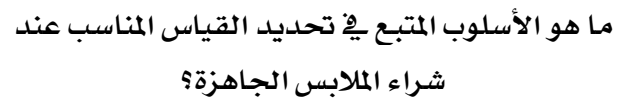 } & \multirow{2}{*}{5} \\
\hline$\%$ & ك5 & & \\
\hline vo & 10. & 1- التجربة ومطابقته على الجسم & $\bar{x}$ \\
\hline • & $1 \cdot$ & r- عن طريق أخذ نصف محيط الصدر & ?) \\
\hline$r$. & $\varepsilon \cdot$ & 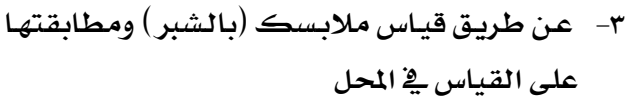 & j \\
\hline
\end{tabular}

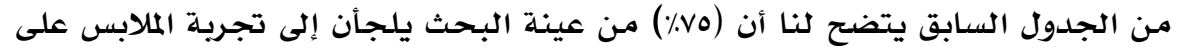

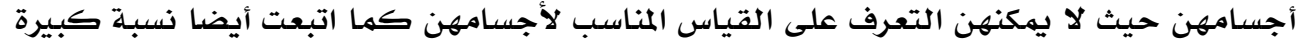

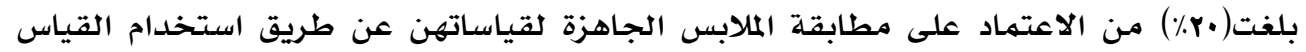

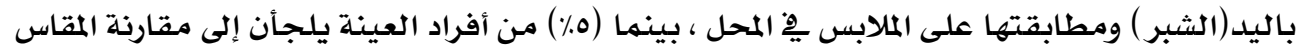

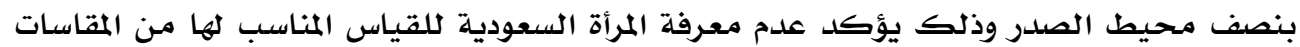
الدولية للملابس الجاهزة وذلك لعدم وجود مواصفات قياسية سعودية وللعدد الكبير من الدول

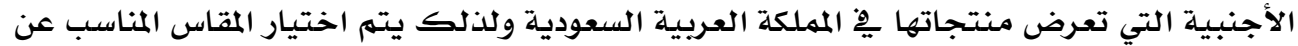

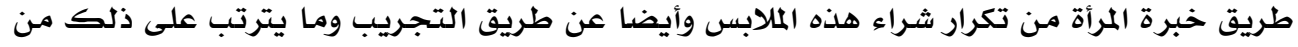

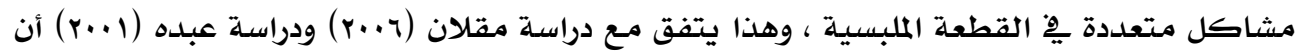

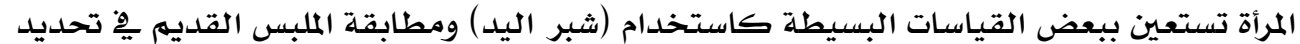

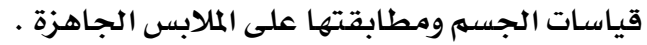
والجدول التالي يوضح الدول المنتجة للملابس ومدىى ملائمسة مقاساتها لجسم المرأة السعودية 
جدول رقم (r)

الدول المنتجهة للمهلابس الجاهزة ومقاسـاتها التي تناسب جسم المرأة السعودية

\begin{tabular}{|c|c|c|c|c|c|c|}
\hline \multicolumn{2}{|c|}{ أحياناً } & \multicolumn{2}{|c|}{ ע } & \multicolumn{2}{|c|}{ نعم } & \multirow{2}{*}{ ما هي الدولة المنتجة للهملابس وتجدي بها مقاسك } \\
\hline$\%$ & ك & $\%$ & ك & $\%$ & ك & \\
\hline vo & 10. & ro & 0. & • & . & أمـريكا \\
\hline$\varepsilon$. & $\wedge$. & 0. & $1 \ldots$ & 1. & $r$. & إيطاليا \\
\hline 70 & ir. & ro & $v \cdot$ & - & - & أسبـانيا \\
\hline 0. & $1 \ldots$ & $\varepsilon Y, 0$ & 10 & $V, 0$ & 10 & فرنسـا \\
\hline$\varepsilon \vee, 0$ & 90 & r. & 7. & Ir,o & ro & تركيا \\
\hline ro & 0. & Tr,o & iro & Ir,o & ro & الصسين \\
\hline 7. & Ir. & r. & 7. & 1. & $r$. & انجلترا \\
\hline$\varepsilon \cdot$ & $\wedge$. & 0. & $1 \cdots$ & 1. & $r \cdot$ & أوروبـا \\
\hline YY,O & £o & $7 \varepsilon$ & IrA & $1 r, 0$ & $r V$ & سوريا \\
\hline Ir,o & $r V$ & vo & 10. & 11,0 & rr & الهند \\
\hline$I V, 0$ & ro & $v \cdot$ & $1 \varepsilon$. & Ir,o & ro & لبـنان \\
\hline
\end{tabular}

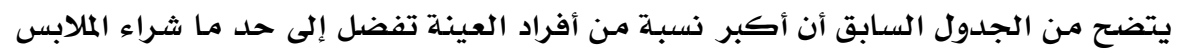

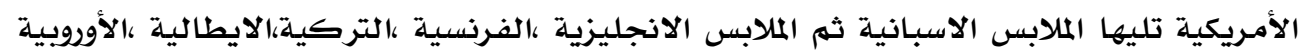

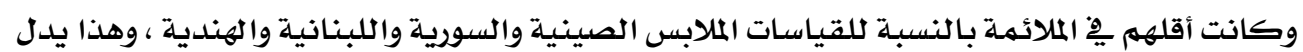
على انه لا توجد مقاسات تناسب جسمى المرأة السعودية، وأيضا اختّلاف المقاسات من دولة إلى إلى أخرى .

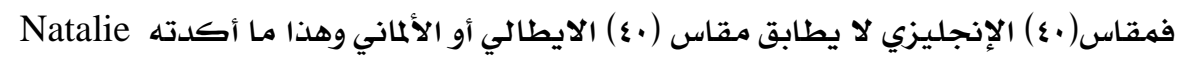

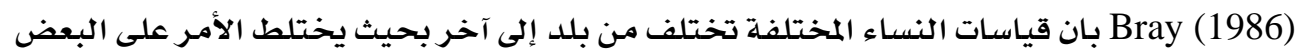

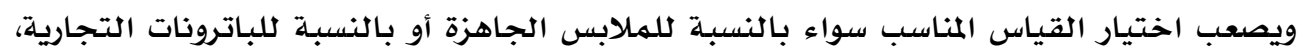

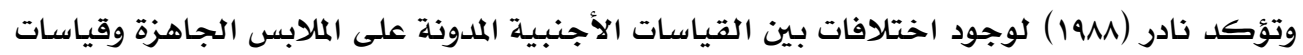

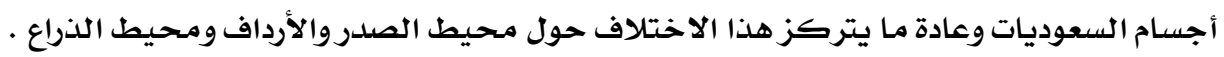
والجدول التالي يوضح ترتيب الدول حسب ملائمة مقاساتها لقياسات جسهم المرأة السعودية 


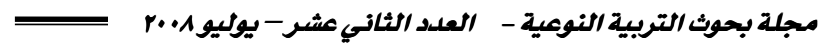

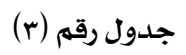

\begin{tabular}{|c|c|c|}
\hline النسبـة & العلدد & ما هي الدوللة المنتجـة للهـلابس وتجلـي بها مقاسك؟ \\
\hline vo & 10. & أمـريكا \\
\hline 70 & Ir. & أسبـانيا \\
\hline v. & 1\&. & انجلترا \\
\hline$\Delta V, 0$ & 110 & فرنسـا \\
\hline 00 & 11. & تركيا \\
\hline 0. & $1 \ldots$ & إيطاليا \\
\hline 0. & $1 \ldots$ & أوروبـا \\
\hline$r v, 0$ & vo & الصسين \\
\hline Tr & VY & سوريا \\
\hline$r$. & 7. & لبنان \\
\hline ro & 0. & الهند \\
\hline
\end{tabular}

من الجدول السابق يتضـح لنا انه على الرغم من كثرة الدول المنتجـة للملابس الجـاهزة إلا

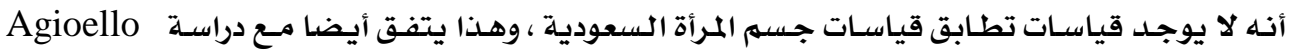

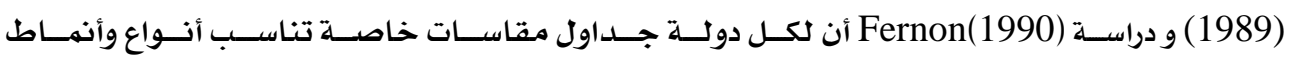

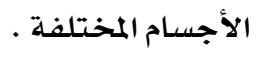

ثانيا : ينص الفرض الثاني على أن :

\section{"هناك مشاكل تواجه المرأة عند اختيار القياس المناسب من الملابس الجاهزة "}

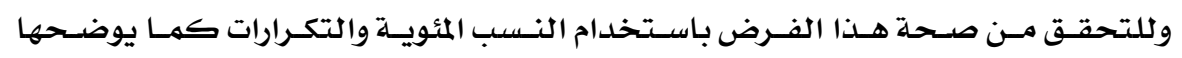

$$
\text { الجدول التالي : }
$$




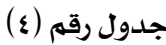

نوعية المشاكل التي تواجـه المرأة عند شراء الملابس الجـاهزة

\begin{tabular}{|c|c|c|c|c|c|c|c|c|c|c|c|c|}
\hline \multicolumn{6}{|c|}{ الجزء السفلي ( جونلة ـ بنطلون ) } & \multicolumn{6}{|c|}{ الجزء العلوي ( بلوزة ـ جاكت ) } & \multirow{3}{*}{ المشاكـل } \\
\hline \multicolumn{2}{|c|}{ 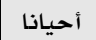 } & \multicolumn{2}{|c|}{ ע } & \multicolumn{2}{|c|}{ نعم } & \multicolumn{2}{|c|}{ 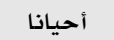 } & \multicolumn{2}{|c|}{ ע } & \multicolumn{2}{|c|}{ نعم } & \\
\hline$\%$ & ك & $\%$ & ك & $\%$ & s & $\%$ & ك & $\%$ & ك & $\%$ & ك & \\
\hline 9 & 11 & 17 & rr & vo,o & 10. & . & . & 11,0 & $r r$ & $\Lambda \wedge, 0$ & ivv & ا. تحتاجين إلى تغيير أو تعديل ِيِ المقاس \\
\hline 11 & r & $1 \%, 0$ & rv & 71,0 & irv & $r \cdot 0$ & « & ir & r & 77,0 & rri & r.عدم مطابقة مقاساتك لقطعة الملابس الجاهزة المختارة \\
\hline r. & $\varepsilon$. & ir,o & ro & TV,O & iro & rr,o & IV & ri,o & $\varepsilon r$ & ¿० & 9. & بـ بوجود فصر من الخلف \\
\hline rq & vs & ro & 0. & ry & vr & $\varepsilon \vee, 0$ & 90 & 19 & rᄉ & rr,o & iv & ؟.وجود قصر ِِّ الأمام \\
\hline- & - & - & - & - & - & 19 & ru & ir & $r \varepsilon$ & 79 & $1 \mathrm{ir}$ & ه. اتساع أو ضيق ٍِِ منطقة الصدر \\
\hline- & - & - & - & - & - & ri & $\varepsilon r$ & rr,o & iv & $\varepsilon 0,0$ & 91 & 7. اتساع أو ضيف ِِِ الأكمام عند أعلى الذراع \\
\hline ir & rr & 11,0 & rv & $7 \cdot 0$ & $|r|$ & Y^.० & ov & YM,O & or & £० & 9. & 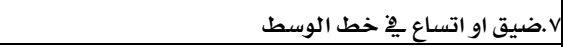 \\
\hline 19 & rᄉ & 19,0 & ra & 71,0 & irr & - & - & - & - & - & - & ᄉ. ضيق او اتساع عند محيط الجناب ( الأرداف) \\
\hline Y $\Lambda, 0$ & ov & ri,o & $\varepsilon r$ & 0. & $1 \cdots$ & 17 & rr & I乏 & rA & 70 & ir. & 9.عدم ملائمة مقاس إحدى القطعتين \\
\hline . & . & r 1,0 & זי & 71,0 & irv & 17 & rr & 9 & 11 & v. & $1 \varepsilon$. & • ا.عدم وجود انسدال يِّ الملبس عند الارتداء \\
\hline
\end{tabular}

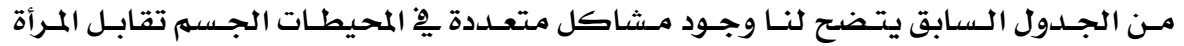

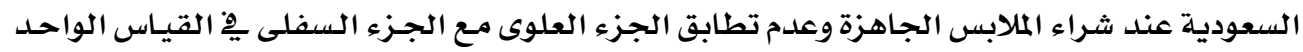

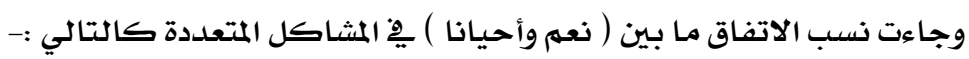

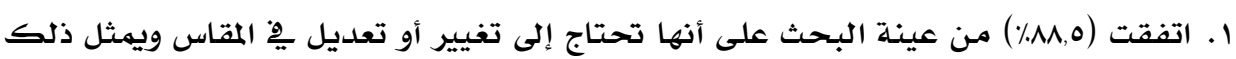

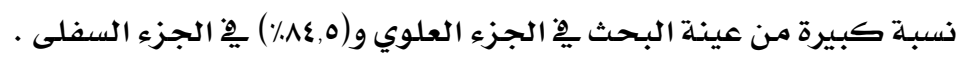

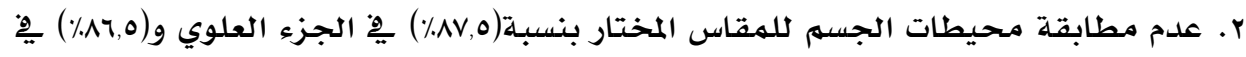

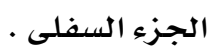

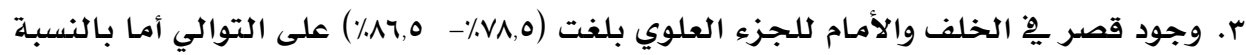

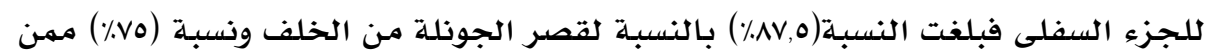

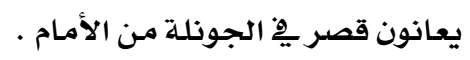

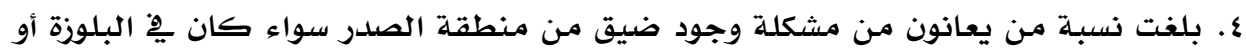

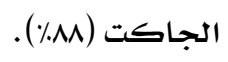

ه. أما بالنسبة لمنطقة الأكمام فكانت النسبة (7,0) وهى مؤشر أيضا لوجود مشكلة عند ارتداء

$$
\text { قطعة الملابس ذات الأكهام . }
$$

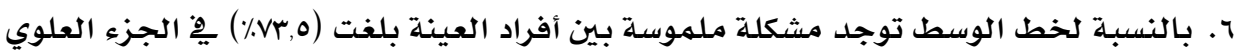

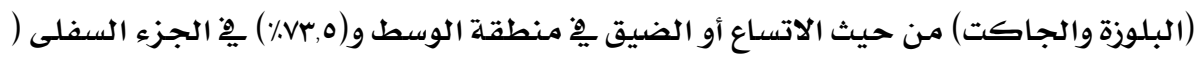

$$
\text { الجونلة والبنطلون) (الجالوزة مالجات }
$$

\section{r.}




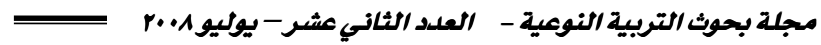

V. وكانت نسبة كبيرة من عينة البحث بلغت ه,•^٪ ممن يعانون من مشكلة عدم مطابقة

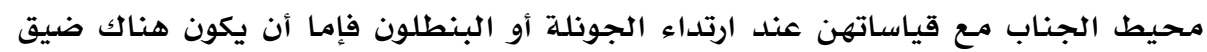

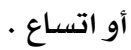

^. وكانت من المشاكل الملحوظة بين أفراد عينة البحث عدم ملائمة مقاس إحدى القطعتين

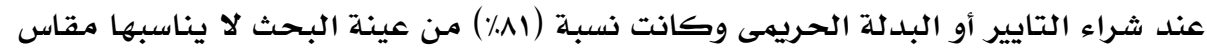

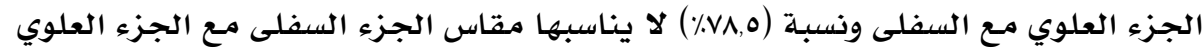

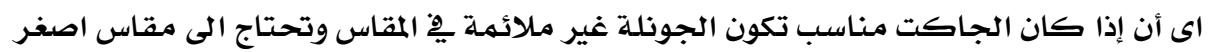

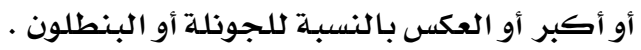

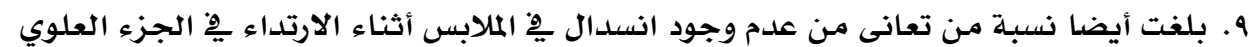

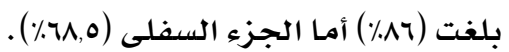

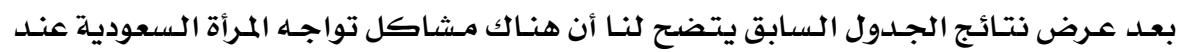

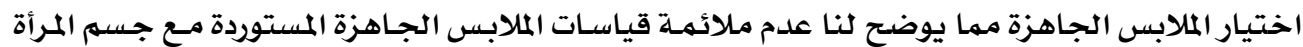

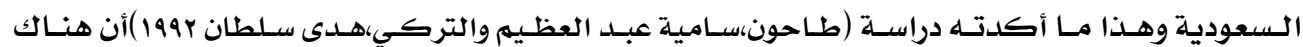

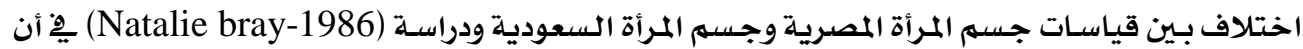

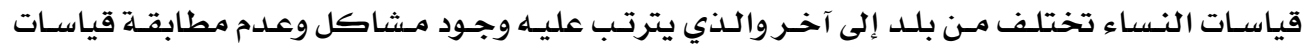

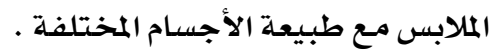

وتتفق أيضا مـع دراسة (ساروخ 1991) التي تؤكد وجود مشاكل ِِّ الملابس الجاهزة مـع أنماط الأجسام المختلفة . وتنفق أبنا

وبذلك يتحقق صحمة الفرض الثاني

ثالثا : الفرض الثالث الذي ينص على :

\section{" يمكن وضع جدول لقياسات جسم المرأة السعودية "}

وللتحقق من صحلة هذا الفرض باستخدام المقاييس الإحصائية الثائعة مثل المتوسط

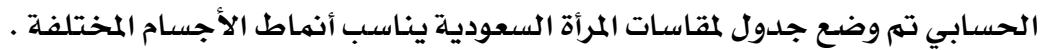

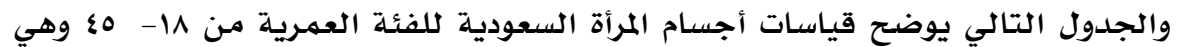

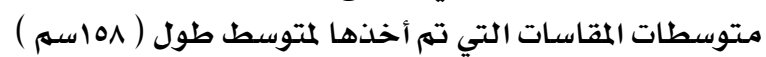




\section{جدول رقم (0)}

جلدول قياسـات المرأة السعوديـة

\begin{tabular}{|c|c|c|c|c|c|c|c|c|c|c|c|c|c|}
\hline r & 7. & $0 \wedge$ & 07 & $0 \leqslant$ & or & 0. & $\varepsilon \wedge$ & $\varepsilon 7$ & $\varepsilon \varepsilon$ & $\varepsilon r$ & $\varepsilon$. & r & \\
\hline Irs & ir. & 117 & $11 \%$ & $1 \cdot 1$ & $1 \cdot \varepsilon$ & $1 \ldots$ & 97 & $9 r$ & $\Lambda$ & $\wedge \varepsilon$ & $\wedge$. & vi & محيط الصدر \\
\hline $11 r$ & $1 \cdot 1$ & $1 \cdot \varepsilon$ & $1 \ldots$ & 90 & 9. & 10 & $\wedge$. & vi & VY & $7 \Lambda$ & $7 \varepsilon$ & Tr & محيط الوسط \\
\hline IrY & 111 & $11 \varepsilon$ & $11 Y$ & $1 \cdot 1$ & $1 . \varepsilon$ & $1 \cdot r$ & $9 \varepsilon$ & 9. & $\Lambda$ & $\wedge r$ & v^ & $v \varepsilon$ & محيط البطن \\
\hline $1 \varepsilon$. & דrו & Irr & דrו & Irr & 111 & lir & $1 \cdot 1$ & $1 \cdot \varepsilon$ & $1 \ldots$ & 97 & ar & $\Lambda$ & محيط الجناب \\
\hline$\varepsilon V$ & $\varepsilon V$ & $\varepsilon 7$ & $\varepsilon 7$ & $\leqslant 0$ & $\varepsilon \varepsilon$ & $\varepsilon \varepsilon$ & $\varepsilon r$ & $\varepsilon r$ & \& & \& & $\varepsilon$. & rq & طول الصدر \\
\hline$\varepsilon \varepsilon$ & $\varepsilon r$ & $\varepsilon r$ & $\varepsilon$ & $\leqslant 1$ & $\varepsilon$. & $\varepsilon$. & rq & rᄉ & rı & rv & rv & דr & طول الظهر \\
\hline$\varepsilon \varepsilon$ & $\varepsilon r$ & $\varepsilon r$ & \&1 & $\varepsilon$. & rq & rᄉ & $r v, 0$ & $r v$ & rq,o & דr & ro,o & ro & عرض الظهر \\
\hline$\varepsilon 7$ & $\varepsilon \varepsilon$ & $\varepsilon r$ & $\varepsilon$. & rᄉ & r & $r \varepsilon$ & rr & $r$. & rی & r & $r \varepsilon$ & rr & محيط الذراع \\
\hline rr & $r$. & $r$. & 19 & 19 & in & M & iv & IV & 17 & 17 & 10 & 10 & محيط الرسيخ \\
\hline ro & $r \varepsilon$ & ع & r & rr & r & rr & rr & rr & m & rl & $r$. & $r$. & طول الكوع \\
\hline זי & Tr & 71 & 71 & 7. & 7. & 7. & 09 & 09 & 09 & $0 \wedge$ & 01 & 01 & طول الذراع \\
\hline
\end{tabular}

معلاحمة:

تم تقريب متتوسطات قياسات الصدر بسماحات د r نلحصول على مقاس زوجي كالمتبع

بالمقاسـات العالميلة وتقريب باقي القياسـات الأخرى لأقرب رقم صحيح (شتا و نادر ، 1999م) . ولقد تم مقارنة هذه القياسـات بهـمهوعة عشوائية من النسـاء السعوديات فوجدت الباحثتان

أن المدى بين المحيطات ثابت كما هو ِِ الجدول مثل محيط الصدر ومحيط الوسط الفرق تقريبا

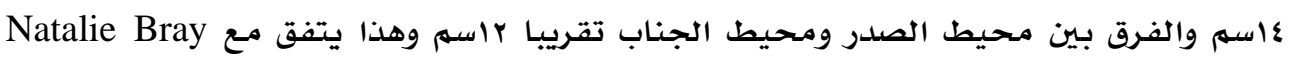

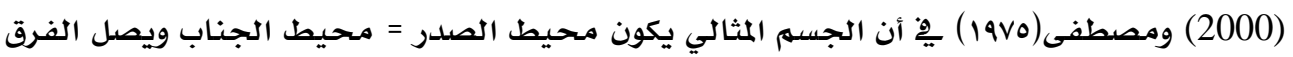

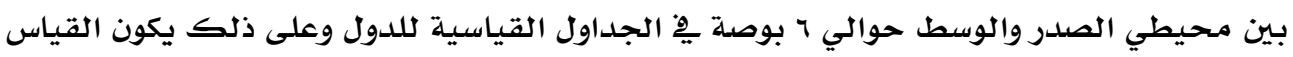

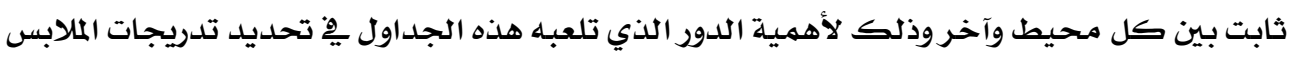
المختلفة عند إنتاج الملابس الجاهزة.

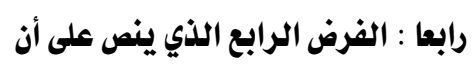

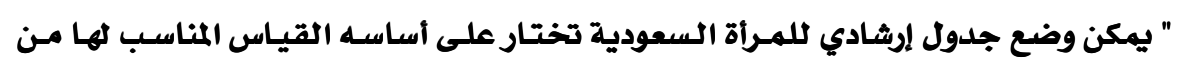

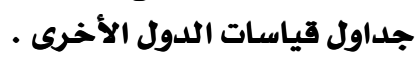

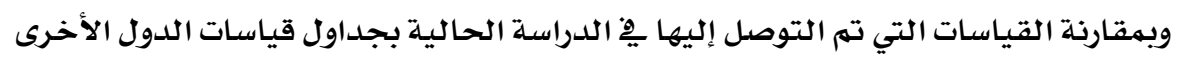

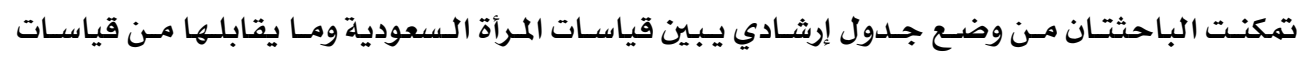

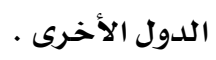
والجدول التالي يوضح مقاسات المرأة السعودية وما يقابلها من مقاسـات الدول الأخرى 


$$
\text { جدول رقم (7) }
$$

علاقة المقاسـات السعودية بـالمقاسـات الأخرى

\begin{tabular}{|c|c|c|c|c|c|c|c|c|c|c|c|c|c|}
\hline Tr & 7. & $O \wedge$ & $0 y$ & $0 \varepsilon$ & or & 0. & $\varepsilon \wedge$ & $\leqslant 7$ & $\varepsilon \varepsilon$ & $\varepsilon r$ & $\varepsilon$. & rی & \\
\hline IrE & ir. & 117 & $11 r$ & $1 \cdot 1$ & $1 \cdot \varepsilon$ & $1 \ldots$ & 97 & ar & $\Lambda \Lambda$ & $\wedge \varepsilon$ & $\Lambda$. & vi & محيط الصدر \\
\hline ঢ & ד & $\pi$ & Ð & せ & $\pi$ & $\pi$ & 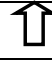 & 1 & オ & ד & 10 & \}1 & المقاسات الدولية \\
\hline r. & Y^ & ry & $Y \varepsilon$ & rY & $r$. & 11 & 17 & 18 & Ir & 1. & $\wedge$ & 7 & الأمـريكية \\
\hline$r$. & Y^ & YY & $r \varepsilon$ & rr & $r$. & 11 & 17 & $1 \varepsilon$ & ir & 1. & $\Lambda$ & 7 & الانجليزية \\
\hline \multirow[t]{2}{*}{07} & of & or & 0. & $\varepsilon \wedge$ & $\varepsilon\rceil$ & $\varepsilon \varepsilon$ & $\varepsilon r$ & $\varepsilon$. & $\mu \wedge$ & דr & rq & rr & الالمانية \\
\hline & & & $0 \xi$ & or & 0. & $\varepsilon \wedge$ & $\varepsilon\rceil$ & $\varepsilon \varepsilon$ & $\varepsilon Y$ & $\varepsilon$. & r^ & דr & الايطالية \\
\hline$\Delta \wedge$ & 07 & of & or & 0. & $\varepsilon \wedge$ & $\varepsilon\rceil$ & $\varepsilon \varepsilon$ & $\varepsilon r$ & $\varepsilon$. & rی & M & r६ & الفرنسية \\
\hline $0 \wedge$ & 07 & of & or & 0. & $\varepsilon \wedge$ & $\varepsilon 7$ & $\varepsilon \varepsilon$ & $\varepsilon r$ & $\varepsilon$. & rᄉ & דr & r६ & المصرية \\
\hline $1 \varepsilon$. & דrו & rri & Iry & IrY & 111 & 114 & $1 \cdot 1$ & $1 \cdot \varepsilon$ & $1 \ldots$ & 97 & ar & $\Lambda$ & محيط الجناب \\
\hline \multirow[t]{3}{*}{ r. } & rı & ry & $r \varepsilon$ & rY & $r$. & 11 & 17 & $1 \varepsilon$ & Ir & 1. & $\wedge$ & 7 & الأمـريكية \\
\hline & $r$. & $r \wedge$ & YT & $r \varepsilon$ & rY & $r$. & $r \cdot$ & 11 & 17 & $1 \varepsilon$ & Ir & 1. & الانجليزية \\
\hline & & or & 0. & 0. & $\varepsilon \wedge$ & $\varepsilon 7$ & $\varepsilon \varepsilon$ & $\varepsilon r$ & $\varepsilon$. & rᄉ & ry & $r \varepsilon$ & الامانية \\
\hline \multirow[t]{3}{*}{$0 \Lambda$} & 07 & of & or & 0. & $\varepsilon \wedge$ & $\varepsilon 7$ & $\varepsilon \varepsilon$ & $\varepsilon r$ & $\varepsilon$. & $\mu$ & Tr & rq & الايطالية \\
\hline & & 07 & $0\}$ & or & 0. & $\varepsilon \wedge$ & $\varepsilon \curlyvee$ & $\varepsilon \varepsilon$ & $\varepsilon Y$ & $\mu$ & rq & $r \varepsilon$ & الفرنسيـة \\
\hline & 07 & of & or & 0. & $\varepsilon \wedge$ & $\varepsilon 7$ & $\varepsilon \varepsilon$ & $\varepsilon r$ & $\varepsilon r$ & $\varepsilon$. & & & المصرية \\
\hline
\end{tabular}

من الجدول السابق يتضح لنا أن المقاسات المقابلة للمقاسات السعودية مقاسات تقريبية

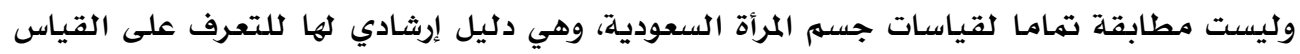

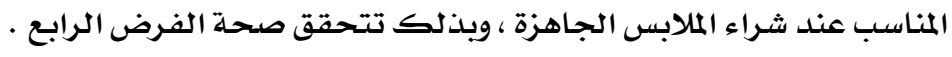

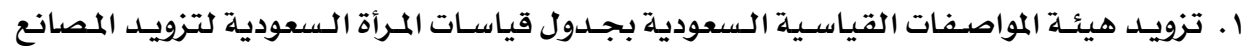

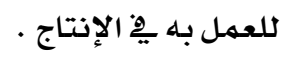

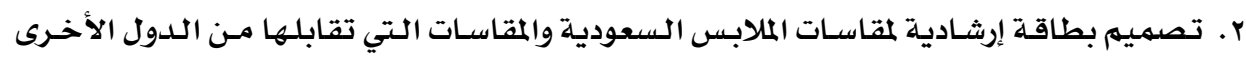

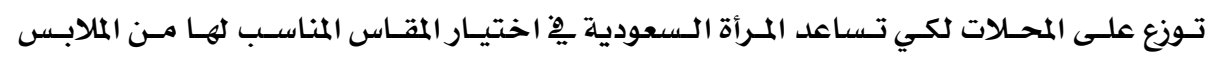

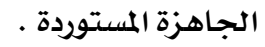

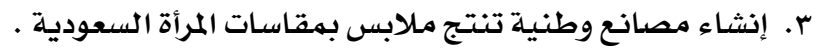

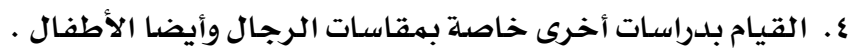




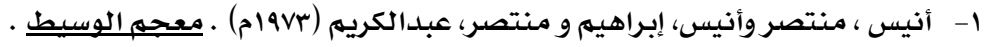

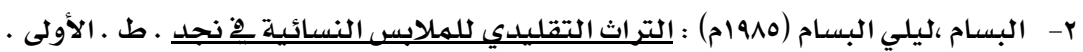

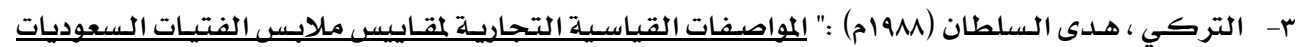
يمنطقة الرياض " رسالة دكتوراه منشورة كلية التربية لكلاقتصاد المنزلي للبنات بالرياض.

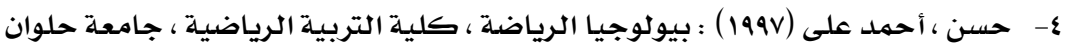

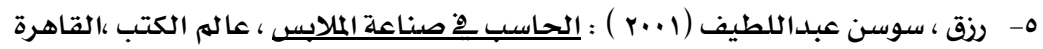

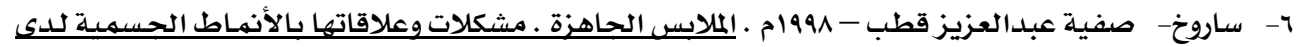

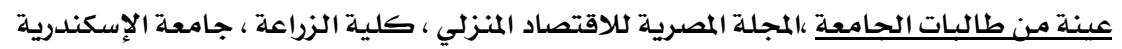

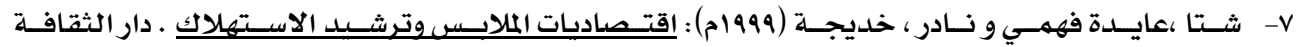

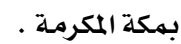
1- شتا ،عايدة محمد فهمي(د.ت) - ندوة جمعيـة رجـال الأعمال(مشروع تنميـة المنشآت الصغيرة والحرفيـة) الإسكندرية.

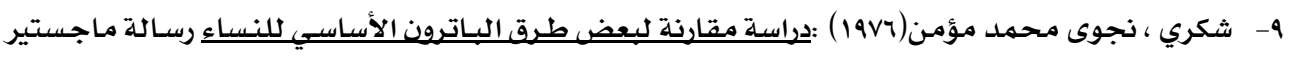

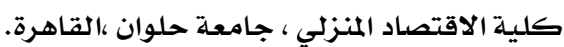

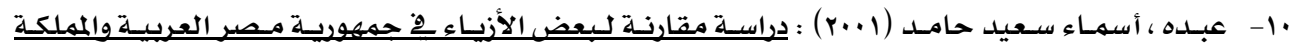

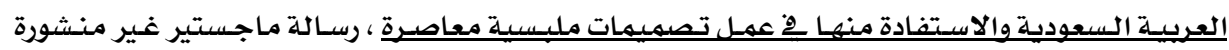
كلية الاقتصاد المنزلي - جامعة المنوفية.

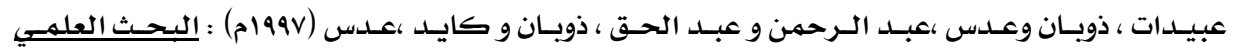

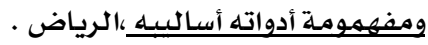

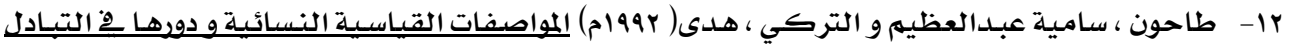

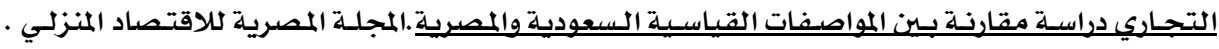

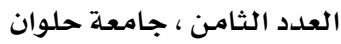

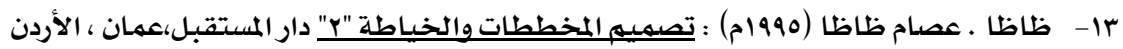

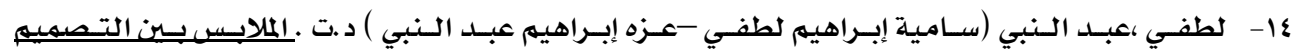

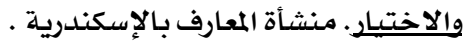

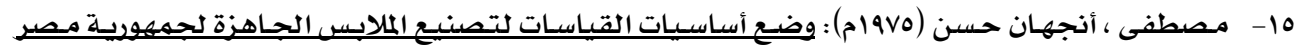

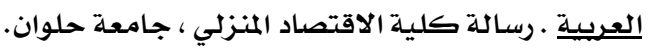

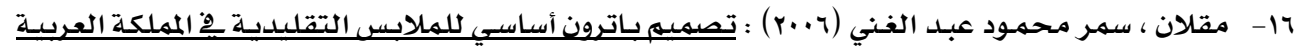

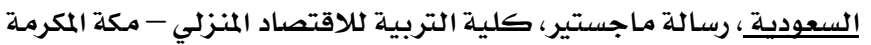

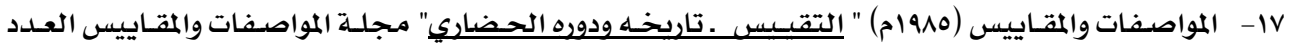

$$
\text { الثاني عشر السنة الخامسة. }
$$

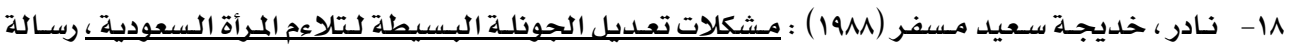

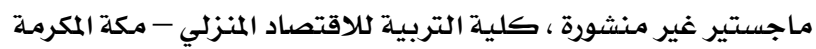




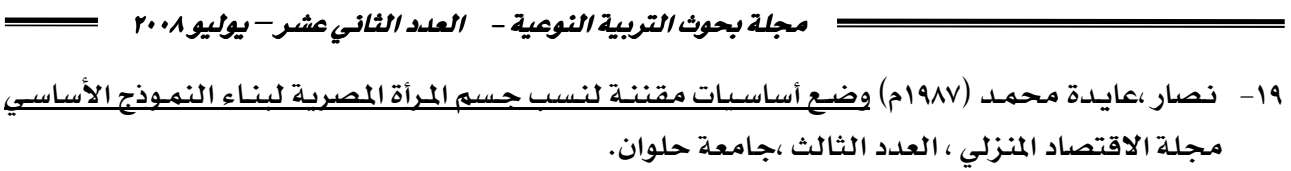

20-Agioello, Debbie: Figure \& Size. Fairchild Publications N.Y. 1989-20

21-Buckbee, j .o.; 'Categorizing bodies according to selected body Measurement of width , depth , and Circumference. Master thesis, Utah state university, 1978, (Inter library loan)

22-Kap- Sum, H, "Comperison Of Anthropometric Measurements of oriental and Caucasian females for sizing systems. Doctoral dissertation, university of North Carolina of Greensboro, 1984.

23-Fernon, Pat: Figure Analysis. TAFE, NSLW. 1990.

24-Natalie Bray:" More Dress, Pattern Designing", Fore edition, 1986, B. London 25-Natalie Bray:" Dress Fitting Basic Principles and Practice:" Blackwell, 2003 


\section{Abstract}

\section{Finding Standard Measurements of the Saudi Women's Body}

\section{Dr. Azza Mohammad I. Salam \\ Dr. Hend Mohammad Arbaeen \\ Lecturer in clothing and Textile \\ Helwan University \\ College of Home Economics \\ Assistant Professor in clothing and Textile Umm Al-Qura University \\ College of Education for Home Economics}

To express a certain measure differs from one country to another, for both garments or commercial patrons. This research aims to limit the problems faced by Saudi women to choose the appropriate garment size, it also aims to give averages legalized for measurements of the body of Saudi women, and then set a directorial table for Saudi Arabia measurements and the corresponding tables of the measurements of other countries. The research followed descriptive analytical method, as applied a questionare on a random sample (200) woman to confine those problems, also the dimensions of the body of the sample (600) woman, from the western region (Makkah-Jeddah-Taif)have been measured, to find the average measurements of Saudi women and then linked them with the international measurements even easier for Saudi women selecting the appropriate size of other sizes. The most important recommendations are as follow :-

1. Providing the Saudi Standard Specifications by tables of measurements of Saudi women body to provide factories to use it in the production.

2. Design a directorial card for garment sizes in Saudi Arabia and the corresponding sizes, by other nations, distributed to shops in order to assist the Saudi woman in choosing the appropriate size of imported garments.

3. Establishment of factories producing national garments with the sizes of the Saudi Woman. 